\title{
25 years of UNCRC: \\ Lessons learned in children's participation
}

\author{
Gerison Lansdown \\ International child rights advocate
}

\section{Introduction}

As we mark the $25^{\text {th }}$ anniversary of the United National Convention on the Rights of the Child (CRC), it is timely to reflect on some of the achievements gained, lessons learned, and challenges ahead. Perhaps nowhere is this more important than in the field of children's participation, a concept which has emerged, in large part, as a consequence of the inclusion of Article 12, and other associated civil rights in the CRC. Their inclusion afforded explicit recognition, for the first time in international law, that children are subjects of rights, entitled to active engagement in the realisation of those rights, in accordance with their evolving capacities. Although children were not excluded from the rights embodied in the International Covenants on both civil and political, and economic, social and cultural rights, these treaties were primarily addressed at adults. Indeed, they both specify that the rights they contain apply to 'men and women'. ${ }^{1}$ While they do contain articles addressed to children in respect of education, health and social, economic and physical protection, the only civil rights included relate to the right to a name and nationality. ${ }^{2}$

The innovation of the CRC was to acknowledge that the way in which children exercise their rights changes with age, but also that, in light of their lack of autonomy, active measures are needed to ensure that they are able to express their views on all matters of concern to them, and to have them taken seriously. In other words, Article 12 goes beyond freedom of expression, to place clear obligations on States to create the time, space and opportunity for children to be heard, and to take the necessary action in response to their views. This principle imposed a radical new set of demands on governments, professionals and civil society organisations, introducing an expectation that they work with and not simply for children. 


\section{Understanding Article 12}

\section{Article 12}

1 States Parties shall assure to the child who is capable of forming his or her own views the right to express those views freely in all matters affecting the child, the views of the child being given due weight in accordance with the age and maturity of the child.

2 For this purpose the child shall in particular be provided the opportunity to be heard in any judicial and administrative proceedings affecting the child, either directly, or through a representative or appropriate body, in a manner consistent with the procedural rules of national law.

In 1989, after the CRC was adopted by the UN General Assembly, there was both excitement and anticipation at the possibilities afforded by Article 12, as well as significant anxiety as to both its implications and scope, and the capacities of adults to adapt their traditional assumptions towards the status of children. The Committee on the Rights of the Child has consistently sought to encourage and support States to invest in measures to give it meaningful effect, and in 2009, published a General Comment clarifying its implications for law, policy, resources and public services. ${ }^{3}$ First and foremost, it emphasises that the requirement that 'States parties shall assure' the right of children to express views, is a strong legal obligation, which leaves no leeway for discretion. ${ }^{4}$ In other words, implementation is not optional, preferable, or to be encouraged. It is mandated. In relation to the specific provisions of Article 12, the Committee has adopted the following interpretation:

- 'the child capable of forming his or her own views': The Committee affirms that no age limit applies to Article 12, and that it interprets 'capable' as applying to children of all ages, the onus being on adults to find ways of eliciting the views of children who are, for example, very young or with disabilities. ${ }^{5}$

- 'right to express views freely': The opportunity to express views requires information, lack of manipulation, safe and respectful spaces and recognition that this is a right not an obligation. Children should never be required to give views. ${ }^{6}$

- 'in all matters affecting the child': All matters is defined very widely, to include not only issues explicitly mentioned in the Convention. It is recognised that children are affected by most areas of public policy including, for example, macro-economics, environment, transport and social protection. ${ }^{7}$ 
- 'due weight in accordance with age and maturity': It is not sufficient to listen to children: their views have to be taken seriously, taking into account their age and maturity. Obviously Article 12 does not mean that whatever children want must be granted, but it does require that they are not simply disregarded. ${ }^{8}$

- 'in any judicial or administrative proceedings affecting the child': The Committee elaborates a very wide interpretation of proceedings to cover all possible contexts that might be relevant to the child. Children must be heard in all civil, criminal, asylum, and administrative proceedings which affect them. The obligation to ensure that children have an opportunity to be heard applies in situations where the child initiates proceedings him or herself, as well as those initiated by others, and proceedings need to be rendered child friendly in order that their participation is meaningful and effective. $^{9}$

The scope of Article 12 has been conceptualised as requiring four core dimensions space, voice, audience and influence. ${ }^{10}$ In addition, the Committee clarifies that Article 12 applies equally to children as individuals, for example, in respect of court hearings or decisions relating to their health care, and to children as a group. The latter could, for example, include all children in a particular school, children in a municipality, or particular groups of children such as girls, children with disabilities, or asylum seeking and refugee children. ${ }^{11}$ While Article 12 itself does not introduce the specific term, the Committee observes that the right of children to be listened to and taken seriously has been encapsulated as the concept of 'participation'. 12

\section{Impact of Article 12}

Article 12 stimulated a huge breadth of activity globally. In all sectors - child protection, education, health, media, water and sanitation, HIV/AIDS, reproductive health, social protection and budgeting - initiatives have been developed to engage children's perspectives and experiences. Innovative and wide-ranging approaches to the participation of children have been adopted, including peer education, research, advocacy, community development, campaigning, and UNCRC reporting. Children have been invited to speak at conferences at local, national and international levels. The transformation in the status of children was perhaps most starkly differentiated in their roles at the World Summit for Children in 1990 and the subsequent UN Special Session on Children in 2002. At the former, 
children were invited in national dress to direct delegates to their seats, whereas at the latter, they contributed to the preparation of the final conference document, participated as delegates themselves, appeared on platforms as speakers, and held their own meetings. And a growing number of different spaces and opportunities for children to engage began to evolve during this period. From the early 1990s, children's parliaments, unions, clubs, and child-led organisations were developed across many regions of the world. In Nepal, for example, thousands of child clubs all over the country were established with the support of international and national NGOs. These clubs represented an expression of democracy and an opportunity for children to learn about and claim their rights. ${ }^{13}$ Hundreds of publications offering guidelines, good practice examples, toolkits, reviews and research evidence have been produced. ${ }^{14}$ Rights respecting schools in which children have a meaningful role to play have been introduced in many countries. ${ }^{15}$

This proliferation of activity has produced significant achievements. ${ }^{16}$ Many countries have introduced laws to establish legal rights for children to be heard - in adoption and care proceedings, in decisions over custody and access, and in criminal proceedings. Quebec, for example, requires the consent of children over the age of 14 in adoption proceedings with a presumption that children aged 10 to 14 should consent. ${ }^{17}$ The consent of children aged 13 and above is required in Poland. ${ }^{18}$ Denmark requires the consent of children over 12 years of age. ${ }^{19}$ Some countries have introduced legal obligations on parents to consult with children in families over major decisions affecting them, or established the right of children to set up democratic school councils. ${ }^{20}$ Reform in a number of countries has led to the establishment of Article 12 as a constitutional right. For example, Ecuador's 1998 Constitution contains extensive references to the rights of children, including the "right to be consulted in matters affecting them. ${ }^{, 21}$ In 1995, the Constitution of Finland was amended by the addition of a sentence providing: "Children shall be treated equally and as individuals and they shall be allowed to influence matters pertaining to themselves to a degree corresponding to their level of development." 22 Children have also been granted rights in respect of the right to identity, name change, change of nationality, and the right to initiate legal actions. ${ }^{23}$

Local and national governments in many countries have acknowledged the importance of giving children a voice in policy making and supported the establishment of youth councils or forums which feed into decision making on relevant issues. In Wales, for example, a Children and Young People's Assembly (Funky Dragon) is a national democratic organisation, comprised of young people elected through local youth forums with a mandate to represent the children of Wales at the national political arena. ${ }^{24}$ More than 200 human 
rights institutions for children have been established in over 70 countries, most of which advocate for enhanced implementation of Article 12, are advised and informed by children themselves and create spaces through which children's voices can be heard. ${ }^{25}$ Member States of the Council of Europe have adopted a Recommendation on Article 12 together with an Assessment Tool providing 10 indicators to help measure progress in its realisation. ${ }^{26}$ The European Union has recently undertaken an evaluation of implementation of Article 12 in all 28 Member States. ${ }^{27}$ The new Optional Protocol to the CRC on a Communications Procedure has recently come into force, providing children with an international mechanism for seeking redress when their rights are violated. ${ }^{28}$ And finally, the developments for the post-2015 agenda place significant emphasis on the need for accountability to ensure the human rights of marginalized and vulnerable groups, including children and youth, are upheld and that they are included in decision-making processes that affect their well-being. ${ }^{29}$

It is possible to claim, therefore, that the decision made by the drafters of the CRC, to include an article dedicated to recognition of the child's right to expression of views, coupled with an obligation to give due weight to those views, has had profound global impact. Beyond the institutional and legal reform it has triggered, it has also begun a process of reconsideration of attitudes towards children. We are witnessing the beginnings of recognition not only that they are entitled to be involved in decisions that affect them, but that they can and do add value to both the process and outcomes of that decision-making.

\section{Continuing challenges}

However, the process of meaningful implementation of Article 12 for all children is very far from complete. Most children in the world continue to be denied a voice, and where progress has been made, it is often inconsistent and partial. Participation is not an easy process. It necessitates profound changes to assumptions and behaviours towards children in cultures throughout the world. There are major challenges to be addressed if the goal of creating a culture of respect for children as subjects of rights, empowered to claim those rights for themselves is to be realised. The following issues provide thought for reflection on some of those challenges and the changes that are needed in order to bring about change: 


\section{Establishing entitlement}

Despite some legislative reform, opportunities for participation are, all too often, project-based opportunities contingent on the good will of adults and short term funding. They are not rooted in sustained and accessible structures open to all children. In order to move beyond such ad hoc approaches to participation, it is imperative that measures are introduced to guarantee participation rights for every child to be heard in all arenas of their lives. Work has been done to construct core indicators against which to measure concrete progress in implementing Article $12 .{ }^{30}$ It suggests that action is needed at three levels:

- Measures to protect the right to participate: An unequivocal commitment to children's right to participate in decisions affecting them and be taken seriously should be enshrined in national primary legislation or constitutions, and backed up in specific laws relating to, for example, child protection, care, and adoption procedures; custody and access in civil proceedings; education; health care, family law, and criminal proceedings. In addition, measures are need to ensure that children are able to exercise the right to be heard in judicial proceedings, and have access to effective, safe and accessible complaints measures.

- Measures to raise awareness of and capacity in participation rights: Rights are not meaningful without information that they exist. Child rights education needs to be embedded in national school curricula ensuring that every child is fully informed about their rights and how to exercise them. All professionals working with children also need training at pre and in service levels to enable them to understand the implications of the $\mathrm{CRC}$ for their individual practice, the institutions or systems within which they work, as well as the public policies that impact on the lives of children with whom they work. Information is also needed at the wider public level to inform parents and the wider society that children have rights, including the right to be heard.

- Measures to create spaces for participation: Children need spaces through which to express their views. Accordingly, local and national governments must introduce structured opportunities through which to hear the voices of children and young people. Public services should create feedback mechanisms through which children can share their concerns, experiences and ideas for improving quality and access. Sustained support is needed to enable children and young people to establish and manage their own organizations and structures through which they can explore their 
own ideas. Schools need to facilitate the creation of genuinely democratic school councils that can influence and inform the day to day life of the school environment.

\section{Building meaningful participation}

One of the barriers to progress on Article 12 has been a lack of clarity over what is meant by participation. It suffers from having an every day meaning, in the sense of taking part in a game or sport, as well as its interpretation under human rights law as elaborated by the Committee on the Rights of the Child in its General Comment. ${ }^{31}$ Clearly, children's right to participate can take many forms all offering different levels of empowerment and influence. However, too often it is considered sufficient merely to seek information from children on a pre-determined adult agenda. The CRC demands more than this. The nature of children's participation can be conceptualised at three levels: $:^{32}$

- Consultative participation arises when adults seek the views of children but afford them no opportunity to influence the nature of the questions, the process of information gathering or the analysis of findings. Children are largely passive in these processes. However, consultative participation can be of real value. A commitment to seeking the perspectives of children demonstrates respect for their contribution, and recognizes that without their views and experiences it is not possible to make informed and appropriated decisions affecting their lives. As such, consultation represents significant progress from the tradition of assuming that adults have all the answers about children's lives: it acknowledges that a commitment to ensuring the best interests of the child needs to be informed by the child him or herself. It is a valid means of enabling children to express their views - for example, when undertaking research, in planning processes, in developing legislation, policy or services, or in decisions affecting individual children within the family, within healthcare or education services, or as witnesses in judicial or administrative proceedings. However, if participation is confined merely to consultation, it restricts children to an exclusively adult-defined agenda, without opportunities to determine the issues on which they themselves wish to focus.

- Collaborative participation offers a greater degree of engagement by children. It arises when adults, having identified an issue that needs to be addressed, involve children in helping to work out what needs to be done and how. In other words, it involves a degree of partnership between adults and children. For example, a 
government might decide to set up a children's rights ombudsman or commissioner. However, having made the initial decision without children, they then involve children in designing the role, drawing up the job description, the recruitment process, and ongoing support and engagement in the work of the official appointed to the role. Children are collaborators in the implementation of the decision. Although the children's ombudsman is a position that is run and managed by adults, it is constantly informed and influenced by children. Accordingly, it is a form of collaborative participation that provides the opportunity for active engagement on an ongoing basis. Collaborative participation with children as individuals can also take place, for example, when decision making within the family or in respect of health care treatment. Research undertaken with sick children in the UK found that many children sought a collaborative approach to taking difficult decisions. They wanted to be directly involved but in discussion with and being supported by their parents. ${ }^{33}$

- Child-led participation takes place when children are provided with the space and opportunity to initiate their own activities and carry out advocacy. Instead of responding to ideas or projects initiated by adults, they create their own structures or organizations through which to determine the issues that are most important to them, and on which they want to take action. The role of adults in child-led participation is to act as facilitators to enable children to pursue their own objectives, by providing information, advice and support. One child-led project in India, for example, identified violence in the home as a consequence of alcohol as one of the most damaging dimensions in their lives. ${ }^{34}$ They undertook research into the location of alcohol sales, the annual sum being spent on alcohol within their community and the positive benefit that this amount of money could purchase if spent on food, clothing and education. They then engaged in advocacy and awareness- raising with community leaders and the police to mobilize a campaign to reduce the level of drinking in the community. In addition, children can initiate action as individuals for example, in choosing a school, seeking medical advice, pressing for the realization of their rights through the courts, or utilizing complaints mechanisms.

It is important to reflect on the nature of participation in which children are engaged and explore with them opportunities to move beyond consultation. Processes that begin as consultative can become more collaborative as both children and adults gain in confidence and understanding. For example, a research project with children can be made collaborative 
by enabling children to identify what the relevant questions are, giving children the opportunity to help develop the methodology for the research, allowing children to take on the role of researchers and involving children in discussions about the findings, their interpretation, and their implications for future developments. Each different level of participation will be appropriate in different contexts. However, it is vital to recognize that if it remains exclusively at the consultative level, very limited opportunities will be created for children to have significant influence over the decisions and actions that impact on their lives.

\section{Acknowledging capacity}

Children are consistently denied opportunities to contribute to or take responsibility for decisions that affect them. Without the opportunity to engage in such processes, they are unable to build experience and competence, the lack of which is often subsequently used to justify further exclusion. Thus, a downward spiral is created. This process arises as childhood is commonly perceived as an extended period of dependence in which children are passive recipients of adult protection, training, wisdom and guidance, rather than contributors to their social environments. ${ }^{35}$ Conventional child development theories have tended to construct children as moving through a process of acquiring maturity according to pre-determined biological and psychological forces, with little recognition of their capacities or agency within it. Presumptions of children as immature learners have led to a failure to value or witness the behaviours they exhibit that testify to their active participation in shaping their own and others lives around them. James and Prout, for example, have argued that because much research into children's lives in the developed world has focused on the child's cultural world - the playground, or child-to-child relationships - it gives too little attention to children's relationships with adults. ${ }^{36}$ In consequence, it affirms the view of children as different, inhabiting a separate and discrete world from adults, and fails to recognize the extent to which children do inform and influence adult behaviours and decision-making and demonstrate capacity to exercise agency in their own lives.

However, cross cultural research consistently reveals that the capacities of children, far from being pre-determined along an age-related trajectory, are, in fact, strongly influenced by context, expectations, culture and levels of support. ${ }^{37}$ For example, at the age of 10 years, Tonga children of both sexes in Zimbabwe are working within their family as farmers, livestock owners and cash earners, often owning and controlling both land and livestock. ${ }^{38} \mathrm{At}$ this age, boys are expected to build their own houses, while girls are considered capable of 
running a household in the absence of an older woman. Children in Peru's asparagus farms are generally regarded as having almost adult competence by the ages of 11 to 14 years, often taking sole responsibility for the cultivation and management of a field ${ }^{39}$ In rural Bolivia, young people from the ages of 13 to 16 years, are involved in negotiating decisions about future work or education and, despite major structural constraints limiting their choices, are nevertheless exercising clear agency in deciding whether to stay in school or to start work, whether to work within the local community or migrate to seek better financial possibilities. Furthermore, they exhibit a strong sense of family responsibility and their choices are heavily influenced by the importance of balancing their own wishes with the needs of the family. The research highlights that young people of this age not only demonstrate the capacity to make informed choices based on realistic assessments of the options available to them, but that in doing so, they are aware of and able to take account of perspectives other than their own. ${ }^{40}$

The CRC acknowledges that, while all the rights embodied in the Convention apply to all children, the capacities and context of the individual child must influence both how they are applied and the degree of autonomy of the child in their exercise. ${ }^{41}$ The principle of respecting the child as an active participant and subject of rights, and not just as a recipient of adult protection, is a theme reiterated throughout the Convention. Article 5 specifically states that guidance to children in the exercise of their rights must be given in accordance with their evolving capacities. As described above, Article 12 emphasizes that the weight given to children's views must take account of their age and maturity. Evolving capacities is also referred to in Article 14 with respect to the right to freedom of thought, conscience and religion. None of these articles identify specific ages at which entitlement to exercise rights transfers to the child. Rather, they allow for recognition of the individual capacities of each child to be respected in relation to each of their rights. They firmly challenge the notion that competence to exercise rights, as opposed to having those rights protected by adults, only commences at the age of 18 years. There is an onus on parents, professionals and the State, to recognize and create opportunities for participation, enabling children to take progressive responsibility for those decisions they are competent and willing to take.

\section{Recognising implications of childhood status}

It is, nevertheless, necessary to acknowledge that children are not adults: accordingly, the implications of strengthening their participation do differ from the implications in respect of adults. A number of critical differences exist. First, and self evidently, childhood is a 
temporary status. Unlike other marginalised groups, such as indigenous people or people with disabilities whose status remains with them for life, children are a constantly evolving and haemorrhaging population. Accordingly, the need for continuous investment in capacity building, outreach, and support is far greater than for other groups. Second, a consistent body of evidence from children themselves indicates that they want and need on-going adult support in participatory initiatives. Children have demonstrated in countless initiatives around the world that they have the skills, capacities, interest and experience to bring to influencing decisions and actions affecting their lives. ${ }^{42}$ However, they also recognise that they lack the time, the access to key policy makers, donors and media that are needed to build sustainable participation. ${ }^{43}$ They also value the administrative and organisational skills that adults can provide, as well as the emotional support. For many children, particularly those who have experienced abuse, neglect, violence or social exclusion, this emotional support can be critical to their sustained engagement.

Finally, children are entitled to a higher level of protection in consequence of their youth and greater vulnerability. This places an additional onus of responsibility on those adults involved in working with them. A balance is required. On the one hand, participation is a key dimension of building children's resilience to violence and exploitation. Empowering children to speak out to challenge violence, and creating avenues for complaints and redress are vitally important in overcoming the silence that has historically characterised violence against children. ${ }^{44}$ However, opportunities for participation must always take account of potential risks - for example, to retaliation for claiming rights, to inappropriate exposure in the media, to exclusion from or rejection by their communities, or to situations where they may be exposed to sexual exploitation. All initiatives to promote participation need to develop clear and comprehensive child protection policies. Their aim must always be to promote and ensure safe participation: protection must not be used as a cover for denying children the right to be heard. Investment in working with families and communities is important in order to build understanding of the value and implications of participation, and to minimize the risks to which children may otherwise be exposed.

\section{Reaching out to all children}

All too often, the children afforded the opportunity to participate are those who are easiest to reach - children in school, the better educated, the more able, the sons and daughters of politicians and professionals. If Article 12 is to be implemented effectively, 
more needs to be done to reach out to those children who live further towards the margins of society - children in prison, children with disabilities, indigenous children, children in the poorest communities, street children. Young children are also commonly excluded from the right to be heard. The CRC demands that all rights apply to all children without discrimination on any grounds. ${ }^{45}$ This requires pro-active investment in overcoming the barriers that impede the realisation of rights including Article 12. Furthermore, Article 7 of the UN Convention on the Rights of Persons with Disabilities places an obligation on States to ensure that children with disabilities are able to exercise their right to participate on an equal basis with other children, and must be provided with disability and age-appropriate assistance to realize that right. ${ }^{46}$

In order to address exclusion and discrimination, investment is needed in:

- Critical review of existing practice: This might involve analysis of both who gets excluded, and whether all children within programmes feel equally accepted and valued. For example, in a recent evaluation of child participation in a project in Ghana, the children realised that they were implicitly excluding large numbers of children because their child club was based in a school and assumed only pupils who were registered should be involved. This practice served to exclude pregnant girls who had been thrown out of school, street children and many HIV/AIDS orphans. ${ }^{47}$ However, until they undertook the review, it had not occurred to either the staff or the children that their policies were in any way restrictive or discriminatory. A preparedness to undertake a critical review, and to ensure that children feel safe to discuss their experiences, is a vital first step in building inclusive and non-discriminatory opportunities for participation.

- Removing the barriers: If groups of children are excluded, the next step is to identify the barriers that impede their meaningful participation. These barriers may arise within programmes, but can also serve to prevent certain groups of children gaining access. They include discriminatory and cultural attitudes, physical barriers, lack of transport, lack of awareness, poverty, fears of parents, or language. Programmes need to work with children themselves within local communities to identify the barriers and explore strategies and approaches to remove them. ${ }^{48}$

- Challenging discrimination: If discrimination and exclusion of marginalised groups is to be overcome, broader commitment is required to tackle its root causes. It may be that research is needed into the nature of discrimination and what works in overcoming it. Professionals working with children not only need capacity building in how to promote participation, but also in how to promote inclusive practice at all levels. Finally, awareness raising and advocacy to build 
understanding of these rights and how to realise them is critical to achieving participation for all children.

\section{Ensuring ethical and quality participation}

Twenty-five years of experimentation and exploration with the implications of Article 12 across the world has led to a huge range of different approaches to its implementation. And with that accumulated experience, an emerging awareness of the parameters of acceptable practice has evolved. This has led to growing concerns, for example, over the manipulation of children to pursue adult agendas, the failure to recognise the potential risks to which participation exposes children, the 'parachuting' of articulate children on to international platforms without follow up support, the selection by adults of children to participate in events without reference to their peers, or consultations which fail to feed back to children how their views have been taken into consideration. There is now a far deeper understanding of the ethical and quality standards that are needed if such work is to be meaningful and safe. In response, and building on work undertaken by Save the Children, the Committee on the Rights of the Child has elaborated nine basic requirements that need to be respected in all circumstances, whether relating to children as individuals or as a group. ${ }^{49}$ Only through appropriate regard for these requirements can children be enabled to fully and effectively contribute their views and influence outcomes. ${ }^{50}$ Participation must be:

- Transparent and informative: Children must be provided with full, accessible, sensitive and age-appropriate information about their participation rights, and how this participation will take place, its scope, purpose and potential impact.

- Voluntary: Children should never be coerced into expressing views against their wishes and they should be informed that they can cease involvement at any stage.

- Respectful: Children's views have to be treated with respect and children should be provided with opportunities to initiate ideas and activities. Adults working with children also need an understanding of the socio-economic, environmental and cultural context of children's lives.

- Relevant: Opportunities must be available for children to express their views on issues of real relevance to their lives and enable them to draw on their knowledge, skills and abilities. Children's participation should build on their personal knowledge - the information and insights that children have about their own lives, their communities and the issues that affect them. 
- Facilitated with child-friendly environments and working methods: The approaches to working with children should be adapted to their capacities. Adequate time and resources should be made available to ensure that children are adequately prepared and have the confidence and opportunity to contribute their views. Consideration needs to be given to the fact that children will need differing levels of support and forms of involvement according to their age and evolving capacities.

- Inclusive: As already highlighted, participation must be inclusive, avoid existing patterns of discrimination, and encourage opportunities for marginalized children, including both girls and boys, to be involved. Programmes also need to ensure that they are culturally sensitive to children from all communities.

- Supported by training: Adults need preparation, skills and support to facilitate children's participation effectively, to provide them, for example, with skills in listening, working jointly with children and engaging them in accordance with their evolving capacities. Children themselves require capacity building to strengthen their skills in, for example, effective communication of their rights, and training in organizing meetings, raising funds, dealing with the media, public speaking and advocacy.

- Safe and sensitive to risk: In certain situations, expression of views may involve risks. Adults have a responsibility towards the children with whom they work and must take every precaution to minimize the risk to children of violence, exploitation or any other negative consequence of their participation. Children must be aware of their right to be protected from harm and know where to go for help if needed.

- Accountable: A commitment to follow-up and evaluation is essential. Children are entitled to be provided with clear feedback on how their participation has influenced any outcomes. Monitoring and evaluation of children's participation needs to be undertaken, where possible, with children themselves.

\section{Learning the lessons}

In recent years, there has been an increasing focus on the need to produce evidence of outcomes in programmes. Governments and donors have argued that in order to justify allocation of funds, evidence of the effectiveness of a particular intervention or process must be demonstrated. The international agenda has been increasingly driven by the search for 
scientific or technical solutions to development challenges that are capable of replication. This approach has posed significant challenges in the field of participation.

Measures to promote and protect the exercise of fundamental human rights should not be contingent on being able to prove that they will produce given results. For example, it would be entirely unacceptable to demand that investment in measures to protect women from violence should be contingent on evidence that it will improve their health and well being, although that may well be a consequence. Rather, the right to protection from violence is a right that is intrinsic to respect for human dignity, and as such must be realised of and for itself. Similarly, action to remove barriers impeding opportunities for people with disabilities to vote should not be contingent on an expectation of any given outcome or result - rather it is an essential commitment consistent with the right of people with disabilities to make free and independent choices with regard to their form of government on an equal basis with other people. The same is true of participation. It is a fundamental right that children should be able to contribute to decisions that affect them, irrespective of what changes might come about as a consequence of their participation.

Furthermore, the struggle to promote realisation of the right of children to be heard constitutes a social movement, in the same way that the civil rights movement and the fight for recognition of the rights of women, and people with disabilities were social movements. Progress in achieving such major social transformations cannot be measured in relation to individual projects or programmes. They involve not only legal reforms but profound changes in social norms and cultural values, and as such evolve through multiple and ongoing activities throughout society over a significant period of time. In these evolutionary processes, change can never be attributed to specific or individual initiatives. Rather, it is the accumulative impact of many thousands of activities that gradually create change. The nature of those activities and their effectiveness will depend on the context in which they take place, and as such are not amenable to exact replication, in the way that medical interventions, such as vaccination programmes, can be replicated.

However, despite these caveats, there is a strong case for seeking to measure children's participation. Only by monitoring and evaluating programmes is it possible to understand what is working and why, as well as to what support and resources are needed to strengthen child participation. Very often, participatory programmes are created without clear objectives, and with no real indicators or benchmarks against which to measure progress. This can lead to frustration on the part of children and young people, and an inability to identify what is needed to improve the programme. A commitment to effective evaluation 
provides a mechanism through which adults can be more accountable to the children with whom they are working.

In response to this challenge, a number of the major international NGOs have worked together over the past few years to develop measurement tools with which to evaluate children's participation. They provide a conceptual framework for analysis of participation using the following approach: ${ }^{51}$

- Scope - what degree of participation has been achieved (consultative, collaborative or child-led), at what stages of programme development, and with which children? In other words - What is being done?

- Quality - to what extent have participatory processes complied with the agreed requirements for ethical and effective practice? In other words - How is it being done?

- Outcomes - what have been the outcomes of children's participation, on children personal development and communities, and on the wider realisation of their rights? In other words - What has changed?

These tools, which were piloted in 9 countries globally over a two year period, revealed that children were extremely interested in a process of closer scrutiny of the projects in which they were involved. In addition, the process served to highlight very positive ways in which those projects could be strengthened as well as helping the children recognise and celebrate the significant outcomes they had achieved through their engagement. ${ }^{52}$

\section{Conclusion}

In establishing the right to be heard and taken seriously, the drafters of the UNCRC unleashed the potential for radical transformation in the lives of children. They posed a profound challenge to their traditional status: lacking autonomy, denied rights of independent decision-making, and excluded from participating in all major decisions affecting their lives. And the past 25 years have led to appreciable progress in law, policy and practice in many countries towards greater recognition of the right of children to be involved in those decisions. They have also resulted in a far greater understanding of what we mean by participation, models of effective and ethical engagement, and recognition of children's capacities to accept greater responsibility for decisions in their own lives than they have traditionally been granted. These lessons need to be acknowledged and shared. There is no 
need for new initiatives to reinvent the wheel - an extensive body of knowledge is available on which to draw and capitalise. However, the process is far from complete. Many millions of children throughout the world are still silenced and impotent to influence either major or minor dimensions of their own lives: required to attend authoritarian schools which deny them the right to question, challenge or discover; lacking access to justice or mechanisms for complaint or redress; forced into marriages without consent; denied opportunities to choose their own religion or friendships; subject to laws and policies which fail to reflect their realities, their best interests or their hopes and aspirations.

Power, and the authority to exercise rights on behalf of the child, is vested in those adults who have responsibility for children - parents, teachers, religious leaders, doctors. Parents are granted, for example, the authority to choose a child's name, select their education, or give consent to medical treatment. Typically, those decisions have been made without reference to the child. Similarly, power to make or inform decisions at the wider societal level - whether in relation to education, health, environment, macro-economics or transport - rests exclusively with adults, without reference to the experiences or perspectives of children. Ultimately, meaningful participation is about a commitment to concede a degree of power. It is easy to take account of children's views when those views coincide with those of adults. The challenge arises when they contradict or threaten adult assumptions. Article 12 does not give children autonomy. It does not demand that children should be granted whatever they wish. Rather, it embodies the recognition that being heard, and being taken seriously is fundamental to the dignity and humanity of every child. This does mean that the traditional power of adults to control without question the lives of children must be qualified. The task ahead is to address the power balance between adults and children to afford all children definitive opportunities to take action to influence their own lives. Participation must move beyond being an ad hoc activity which privileges the few to become an entitlement for every child in all spheres of their lives. The goal must be for cultural change towards participatory inclusion at all levels of society. The journey has started. The onus now rests with everyone committed to the human rights of children to keep the momentum going. 


\section{Notes}

${ }^{1}$ International Covenant on Economic, Social and Cultural Rights, Article 3, and International Covenant on Civil and Political Rights, Article 3

${ }^{2}$ International Covenant on Civil and Political Rights, Article 24

${ }^{3}$ CRC General Comment No. 12 The Rights of the Child to be Heard, CRC/C/GC/12, July 2009

${ }^{4}$ CRC General Comment No. 12 The Rights of the Child to be Heard, CRC/C/GC/12, para 19

${ }^{5}$ CRC General Comment No. 12 The Rights of the Child to be Heard, CRC/C/GC/12, para 21

${ }^{6} \mathrm{CRC}$ General Comment No. 12 The Rights of the Child to be Heard, CRC/C/GC/12, paras 22-25

${ }^{7}$ CRC General Comment No. 12 The Rights of the Child to be Heard, CRC/C/GC/12, paras 26-27

${ }^{8}$ CRC General Comment No. 12 The Rights of the Child to be Heard, CRC/C/GC/12, paras 28-29

${ }^{9}$ CRC General Comment No. 12 The Rights of the Child to be Heard, CRC/C/GC/12, paras 32-34

${ }^{10}$ Lundy L and Welty E, A children's rights-based approach to involving children in decision making

${ }^{11}$ CRC General Comment No. 12 The Rights of the Child to be Heard, CRC/C/GC/12, para 9

${ }^{12}$ CRC General Comment No. 12 The Rights of the Child to be Heard, CRC/C/GC/12, para 13

${ }^{13}$ The Children's Clubs of Nepal,: A Democratic Experiment, Save the Children Norway, 1999

${ }^{14}$ See, for example, Child and Youth participation Resource Guide, UNICEF, 2006

${ }^{15} \mathrm{See}$, for example, http://www.unicef.org.uk/Education/Rights-Respecting-Schools-Award/

${ }^{16}$ O’Donnell, Daniel (2009), 'The Right of Children to be Heard: Children's right to have their views taken into account and to participate in legal and administrative proceedings',

Innocenti Working Paper No. 2009-04, UNICEF Innocenti Research Centre, Florence.

${ }^{17}$ Civil Code, articles 549-550. (If a child aged 10 to 14 refuses consent, the court may postpone a decision on adoption or overrule the child.)

${ }^{18}$ Second Report of Poland, op. cit., para. 111, citing article 118.1 of the Family and Guardianship Code.

${ }^{19}$ Third Report of Denmark, op. cit., paras 98 and 450.

${ }^{20}$ Lansdown G (2011) Every Child's Right to be Heard, Save the Children/UNICEF, London

${ }^{21}$ Article 49, “... El Estado les asegurará y garantizará el derecho ... a ser consultados en los asuntos que les afecten", available at the website of Georgetown University

${ }^{22}$ Constitution of Finland, chapter 2 - Basic rights and liberties, section 6 - Equality, para. 2 (731/1999).

${ }^{23}$ O'Donnell, Daniel (2009), 'The Right of Children to be Heard: Children's right to have their views taken into account and to participate in legal and administrative proceedings', Innocenti Working Paper No. 2009-04, UNICEF Innocenti Research Centre, Florence

${ }^{24} \mathrm{http}: / /$ www.funkydragon.org/en/

${ }^{25}$ Championing Children's Rights: A Global Study of Independent Human Rights Institutions

${ }^{26}$ Recommendation CM/Rec(2012)2 of the Committee of Ministers to member States on the participation of children and young people under the age of 18; Council of Europe Child Participation Assessment Framework, Council of Europe, 2014, ${ }^{27}$ forthcoming

${ }^{28}$ Optional Protocol to the Convention on the Rights of the Child on a communications procedure, A/RES/66/138 of 19 December 2011

${ }^{29}$ Progress report of the Open Working Group of the General Assembly on Sustainable Development Goals, http://sustainabledevelopment.un.org/owg.html

${ }^{30}$ these measures are described in more detail in: Lansdown G and O'Kane C, (2014)A Toolkit for Monitoring and Evaluating Children's Participation, Booklet Two, Save the Children/WVI/Plan/ UNICEF/The Concerned for Working Children; and in Child Participation Assessment Tool, Council of Europe, 2014

${ }^{31}$ CRC General Comment No. 12 The Rights of the Child to be Heard, CRC/C/GC/12,

${ }^{32}$ Lansdown G and O'Kane C, (2014)A Toolkit for Monitoring and Evaluating Children's Participation, Booklet Three, Save the Children/WVI/Plan/ UNICEF/The Concerned for Working Children,

http://www.savethechildren.org.uk/resources/online-library/toolkit-monitoring-and-evaluating-childrens-participation,

${ }_{33}$ Alderson P (1993) Children's Consent to Surgery, OUP, London

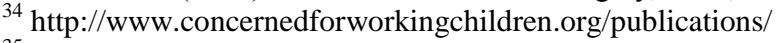

${ }^{35}$ Lansdown G (2005) The Evolving Capacities of the Child, Innocenti research Centre, UNICEF, Florence

${ }^{36}$ James, A., Childhood Identities: Self and Social Relationships in the Experience of the Child, Edinburgh University Press, Edinburgh, 1993.

${ }^{37}$ Lansdown G (2005) The Evolving Capacities of the Child, UNICEF Innocenti research Centre, Florence

${ }^{38}$ Reynolds, P., 'Children in Zimbabwe: rights and power in relation to work', Anthropology Today, June 1985, Vol. 1,

${ }^{39}$ No. 3, p. 17. 171 Mendoza I, Trabajo Infantil rural en el Peru; la agricultura de esparragos en la costa norte, ILO, INTERDEP/CL/1993/2, cited in Boyden, J., B. Lingand W. Myers, What works for working children, Radda Barnen/UNICEF, Stockholm, 1998.

${ }^{40}$ Punch, S., 'Youth transitions and interdependent adult- child relations in rural Bolivia',Journal of Rural Studies, 2002, Vol. 18 (2), pp. 123-133.

${ }^{41}$ Van Beuren, G., The International Law on the Rights of the Child, Save the Children/Martinus Nijhoff, Dortrecht, 1995.

${ }^{42}$ Check reference

${ }^{43}$ see for example, The Wheel of Change: Children and Young People's Participation in South Asia, UNICEF ROSA, Kathmandu, 2004

${ }^{44}$ Lansdown G (2005) The Evolving Capacities of the Child, Innocenti research Centre, UNICEF, Florence 


\footnotetext{
${ }^{45}$ UNCRC, Article 2

${ }^{46}$ for further information, see Lansdown G (2009) See Me Hear Me: A Guide to Using the Convention on the Rights of persons with Disabilities to Promote the Rights of Children, Save the Children, London

${ }^{47}$ direct experience of author with the project

${ }^{48}$ see, for example, Take us Seriously: Engaging Children with Disabilities in Decisions affecting their Lives, UNICEF, 2014

${ }^{49}$ CRC General Comment No. 12 The Rights of the Child to be Heard, CRC/C/GC/12,

${ }^{50}$ Lansdown G and O'Kane C, (2014)A Toolkit for Monitoring and Evaluating Children's Participation, Booklet Three, Save the Children/WVI/Plan/ UNICEF/The Concerned for Working Children,

http://www.savethechildren.org.uk/resources/online-library/toolkit-monitoring-and-evaluating-childrens-participation, ${ }^{51}$ Lansdown G and O'Kane C, (2014)A Toolkit for Monitoring and Evaluating Children's Participation, Booklet Three, Save the Children/WVI/Plan/ UNICEF/The Concerned for Working Children, Booklet Three

http://www.savethechildren.org.uk/resources/online-library/toolkit-monitoring-and-evaluating-childrens-participation,

${ }^{52}$ Lansdown G and O'Kane C, (2014)A Toolkit for Monitoring and Evaluating Children's Participation, Booklet Three, Save the Children/WVI/Plan/ UNICEF/The Concerned for Working Children, Booklet Six

http://www.savethechildren.org.uk/resources/online-library/toolkit-monitoring-and-evaluating-childrens-participation,
} 